\title{
"Ahora que lo antiguo se ha vuelto moderno": los pioneros del nuevo tango canción en la década del noventa
}

\section{Artículo de investigación}

\section{Julia Winokur}

Instituto de Altos Estudios Sociales, Universidad Nacional de San Martín, Argentina

winokur.julia@gmail.com

Recibido el: 05/05/2020

Aceptado el: 11/09/2020

Cómo citar este artículo: Winokur, J. (2021). "Ahora que lo antiguo se ha vuelto moderno": los pioneros del nuevo tango canción en la década del noventa. Calle 14: revista de investigación en el campo del arte. 16(30), pp.262-275. https://doi.org/10.14483/21450706.18298 


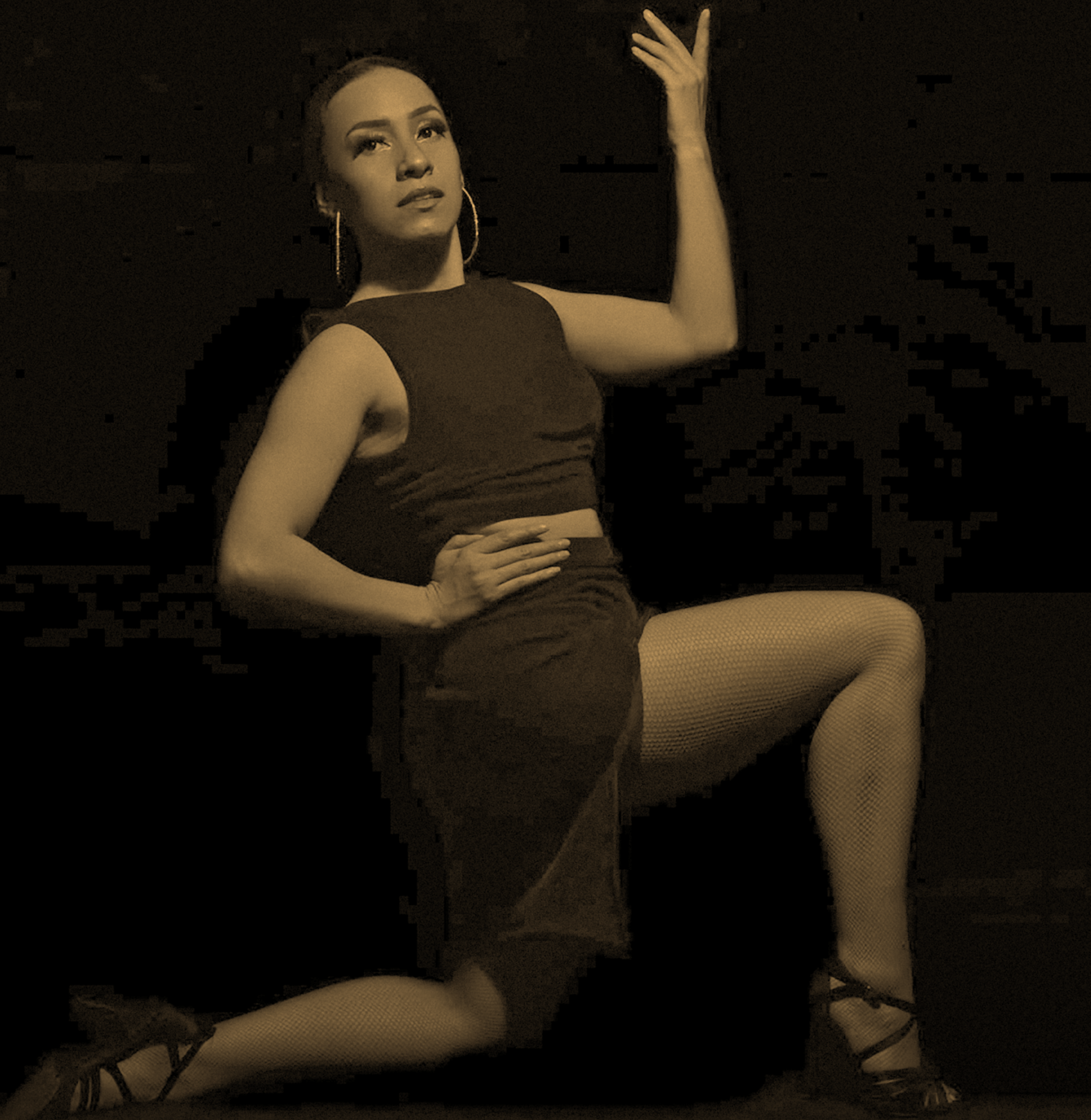


"Ahora que lo antiguo se ha vuelto moderno": los pioneros del nuevo tango canción en la década del noventa

\title{
Resumen
}

En este trabajo nos proponemos analizar las primeras formaciones de tango aparecidas en la década de los noventa lideradas por cantautores. Nos enfocaremos en la primera producción discográfica de tres artistas, "Acho" Estol, "Tape" Rubín y Juan Vattuone, por considerarlos iniciadores de una nueva generación y por su vasta producción e influencia en los compositores y autores que les siguieron. Encontramos que estos músicos eligen como tradición la estética del tango de las décadas del veinte y el treinta, previo a la 'década de oro', cristalizada en el imaginario social como el tango. Esto se puede ver tanto en la instrumentación como en la poesía, que recupera el humor y la denuncia social que el tango perdió posteriormente. Sin embargo, esta tradición no se toma en forma de homenaje 'puro', sino combinando estos elementos con rasgos del rock nacional, el blues y el folclore, y mezclando tópicos clásicos del tango con temas y vocablos de la actualidad.

\section{Palabras claves}

Acho Estol; cantautores; Juan Vattuone; nuevos compositores; tango actual; Tape Rubín

"Now that the old has become modern": the pioneers of the new tango song in the nineties

\begin{abstract}
We propose to analyze the first tango formations that appeared in the nineties led by singersongwriters. We will focus on the first record of three artists, "Acho" Estol, "Tape" Rubín and Juan Vattuone, because we consider them to be the initiators of a new generation, and also due to their vast production and influence on the composers and authors that followed. We find that these musicians choose as a tradition the aesthetics of tango from the twenties and thirties, prior to the 'golden decade', crystallized in the social imaginary as Tango. This can be seen both in the instrumentation and the poetry, which recovers the humor and social denunciation that tango subsequently lost. However, this tradition is not taken in the form of a 'pure' tribute, but by combining these elements with features of national rock, blues and folklore, and mixing classic tango subjects with current themes and words.
\end{abstract}

\section{Keywords}

Acho Estol; singer-songwriters; Juan Vattuone; new composers; current tango; Tape Rubín

« Maintenant que lsancien est devenu moderne »: les pionniers de la nouvelle chanson de tango dans

\section{Résumé}

Dans cet article, nous nous proposons d'analyser les premières formations de tango apparues dans les années 90 dirigées par des auteurs-compositeurs-interprètes. Nous nous concentrerons sur la première production de trois artistes, « Acho » Estol, « Tape » Rubín et Juan Vattuone, comme les initiateurs d'une nouvelle génération et en raison de leur vaste production et de leur influence sur les compositeurs et auteurs qui ont suivi. On constate que ces musiciens choisissent comme tradition l'esthétique du tango des années vingt et trente, antérieure à la « décennie dorée », cristallisée dans l'imaginaire social comme le Tango. Cela se voit aussi bien dans l'instrumentation que dans la poésie, qui retrouve l'humour et la dénonciation sociale que le tango a perdu par la suite. Cependant, cette tradition n'est pas prise sous la forme d'un 
hommage « pur », mais en combinant ces éléments avec des caractéristiques du rock national, du blues et du folklore, et en mélangeant des sujets du tango classique avec des thèmes et des mots actuels.

Mots clés

Acho Estol ; compositeurs-interprètes ; Juan Vattuone ; nouveaux compositeurs ; tango actuel ; Ruban Rubin

"Ahora que lo antiguo se ha vuelto moderno": os pioneiros do novo tango canção na década

\section{Resumo}

Neste trabalho, nos propomos analisar as primeiras formações de tango da década de noventa lideradas por cantores/compositores. Nos enfocaremos na primeira produção discográfica de três artistas, "Acho" Estol, "Tape" Rubín e Juan Vattuone, por considerá-los iniciadores de uma nova geração e, por sua vasta produção e influência nos compositores e autores que os seguiram. Encontramos que, estes músicos elegem como tradição a estética do tango das décadas de vinte e trinta anterior a "década de ouro", cristalizada no imaginário social como o tango. Isso se pode ver tanto na instrumentação como na poesia que recupera o humor e a denúncia social que o tango perdeu posteriormente. Porém, esta tradição não é tomada na forma de homenagem "pura", senão, combinando estes elementos com características do rock nacional, o blues e o folclore, e misturando tópicos clássicos do tango com esses temas e vocábulos da atualidade.

\section{Palavras chave}

Acho Estol; cantores/compositores Juan Vattuone; novos compositores; tango atual; Tape Rubín

\section{"kunaura llugpamanda kaskata ikuti kawanakunchi". Tunai ruraska iskun chunga watapi}

\section{Maillallachiska}

Maillallachiska kaipi Munanaku tukuikuata parlangapa ñugpamanda tunai ruraskata iska runakuna kasa suti "Acho" Estol, "Tape" Rubín y Juan Vattuone, paikuna kallariskakuna paikunalla tunaikuna rurai nispa katichii kallariskakuna sugkuna kunan puncha tiami llapa Achka tunai mana kanchu ñugpasina chupu chapu ruraspa apanaku katichispa.

\section{Rimangapa Ministidukuna}

Acho Estol; cantautores; Juan Vattuone rura chasa suti; rura tunai kilkadur chasa suti runa; kunauramanda kikkagkuna; tunai kunauramanda; runa chasa suti Tape Rubín 


\section{Introducción}

"No sé si estoy vivo

Soy joven o viejo

Ahora que lo antiguo

Se ha vuelto moderno."

Acho Estol (2000)

A partir de fines de la década del cincuenta y sobre todo durante las décadas del sesenta y setenta, se produce una fuerte crisis en el tango, con una notoria merma en su producción, difusión y circulación. Por esos años, muchos de los espacios en donde se tocaba y bailaba tango, cierran o cambian de género musical ${ }^{1}$, la mayoría de las orquestas se disuelven o disminuyen notablemente el número de músicos, y el público joven vuelca su atención hacia otras músicas, como el rock y el folklore.

El resurgimiento del tango comienza a gestarse a mediados de la década del ochenta y comienzos de la década del noventa, con la fundación de instituciones educativas y espacios de difusión en los medios de comunicación, como la Escuela de Música Popular de Avellaneda (EMPA), creada en 1986. Allí se reanudó el entusiasmo por el estudio y la transmisión intergeneracional entre los viejos conocedores del género, como Horacio Salgán y Rodolfo Mederos, y los jóvenes estudiantes de música. Además, por esos años se crea la Academia Nacional del Tango, el canal Solo Tango y la FM Tango (Adorni, 2016).

Con este impulso, hacia mediados de la década del noventa, aparece en escena una nueva generación de músicos dedicados al tango, denominada, según diferentes autores, 'tango nuevo', 'tango joven' o 'tango actual' (Mertz, 2018, p. 27). Su producción se desenvuelve en dos frentes casi simultáneamente. Por un lado, hay un rescate de la orquesta típica, con la conformación de la Orquesta Típica Fernández Branca y el colectivo La Máquina Tanguera, ${ }^{2}$ dirigidas por músicos

1 El caso de la milonga Marabú es representativa de este proceso. Fundada en 1935 y ubicada en la zona céntrica de la Ciudad de Buenos Aires, fue un espacio emblemático con relación al tango, por el que pasaron las orquestas más importantes de la época, como la de Anibal Troilo, Carlos di Sarli y Osvaldo Pugliese, entre otras. Cerró sus puertas a mediados de la década del sesenta. Después de sucesivas aperturas y cierres en los que pasó a ser escenario de bandas de rock nacional y discoteca. Desde 1994 funciona nuevamente como milonga, rebautizada Maracaibo.

2 La Orquesta Típica Fernández Branca se conforma en 1998. En 1999 se crea el colectivo La Máquina Tanguera, cuyos integrantes vinculados a la entonces joven EMPA. Estas orquestas se organizan en cooperativas, inspiradas en el modelo de Osvaldo Pugliese ${ }^{3}$ y comienzan tocando los clásicos del tango instrumental de la época de oro, ${ }^{4}$ transcribiendo arreglos originales y escribiendo propios, según el modelo tradicional para orquesta típica (Marcos, 2012).

Por otro lado, por los mismos años, sino pocos antes, comienzan a salir a los escenarios los primeros nuevos autores de tango-canción (cantautores) como 'Acho' Estol, Alfredo 'Tape' Rubín y Juan Vattuone, que escriben tangos con letras y músicas propias y tocan en formatos más pequeños, por decisión estética y, probablemente, también por motivos económicos. Con el paso de los años, estos dos caminos confluirían, hasta llegar al momento actual, en el que muchas orquestas típicas interpretan las composiciones de estos nuevos autores.

La bibliografía que aborda a los que aquí denominamos 'pioneros' de la renovación del tango, generalmente hace referencia al rol de las orquestas y presta poca atención a los autores que ejecutan sus repertorios acompañados por pequeñas formaciones. Por ejemplo, los trabajos de Camila Juárez y Martín Virgili (2012) y de Angélica Adorni (2016) analizan, desde diferentes perspectivas, las primeras orquestas típicas formadas en los noventa, centrándose en la Orquesta Típica Fernández Fierro y su performance rupturista del imaginario cristalizado en la tradición del tango.

Por otra parte, los trabajos que analizan la producción de los autores que en el mismo período se encontraban componiendo y tocando tangos, por fuera del formato orquestal, suelen abordar el tema de la letra (Amato, 2016; Lakner, 2017; Linardi, 2012; Mertz, 2018; Ocantos, 2016), pero prácticamente no encontramos análisis que aborden conjuntamente aspectos poéticos y musicales. Por último, entre los autores que sí analizan pequeñas formaciones, encontramos el trabajo de James Luker (2007) y el de Greco (2012), que toman el caso de 34

provenían mayoritariamente de la EMPA, y que dio lugar a la creación de un gran número de orquestas típicas en un corto período de tiempo.

3 Llamamos 'el modelo Osvaldo Pugliese' tanto a la modalidad de trabajo cooperativo que este músico implementó en la distribución de tareas y ganancias, así como también a las características estilísticas de la sonoridad de su orquesta.

4 Se le llama 'la época de oro del tango' al período que va aproximadamente de los años cuarenta a mediados de los cincuenta del siglo XX. Si bien el tango ya había tenido su explosión discográfica y de baile en las milongas, este período se caracteriza por la proliferación de orquestas típicas y sobre todo por la diferenciación de sus estilos musicales. 
puñaladas, grupo conformado a finales de la década del 90, que comenzó tocando versiones de tangos antiguos.

En este trabajo nos proponemos analizar, entonces, las primeras formaciones de tango de la década del noventa lideradas por cantautores. Para lograr esto, nos enfocaremos en tres artistas 'pioneros': 'Acho' Estol, Alfredo 'Tape' Rubín y Juan Vattuone, por considerarlos iniciadores de una nueva generación y por su vasta producción e influencia en los autores que les siguieron. Abordaremos el primer trabajo discográfico de cada uno de estos autores para analizar su propuesta estética (musical y poética), cuál es la novedad que proponen y con qué tradiciones establecen diálogos. En particular, nos detendremos en las composiciones originales de tangos con letra incluidas en estos discos.

\section{Los pioneros del tango canción}

Ahora bien, un aspecto que caracteriza a los tres autores aquí analizados es que plantean una estética nueva en el tango canción. Al igual que las mencionadas orquestas típicas, incorporan elementos de la tradición del tango para reformularlos a partir del diálogo con otros géneros musicales (como el rock y el folclore), así como con el vocabulario y los temas de la actualidad. Aunque sus producciones tienen puntos de convergencia tanto como elementos que las distancian, se observa como factor común la oposición al modelo de los Grandes Valores del Tango, ${ }^{5}$ que funciona como imagen congelada e intocable de la tradición, y al tango for export, que predomina en los grandes teatros y locales turísticos de ese momento (y la actualidad) en Buenos Aires.

Además, si bien la denominada época de oro fue el período que quedó cristalizado en el imaginario cultural como 'El tango', con la orquesta típica como formato instrumental y el dramatismo, la nostalgia y la melancolía como tópicos característicos de la poesía (Ocantos, 2016), no es este el momento de la tradición que estos nuevos compositores toman como referencia o punto de partida. El período del que se reconocen herederos, en cambio, es el del primer tango canción de las décadas del veinte y treinta, en cuyas letras predominan las referencias al barrio del compadrito reo, con su culto al coraje, el humor, y también, aunque en menor medida, la denuncia de las injusticias sociales. En una entrevista del año 2003, Juan Vattuone explica: Simplemente, a veces tomamos la raíz humorística que tenía el tango en sus orígenes. Esa raíz se dejó de lado después de que el tango romántico copó la parada. Del '40 para acá no pasó casi nada. El tango dejó de hablar de lo que pasa. En este país hubo treinta mil desaparecidos, y ningún tango lo cuenta (Vattuone, citado en Micheletto, 2003, PÁGINA. 5)

Este diálogo que establecen las nuevas letras con el tiempo presente, opera como un certificado de legitimidad a la hora de defender su lugar en la historia del tango y en la escena cultural actual.

\section{"Acho" Estol: ayer hoy era mañana}

El primer disco de La Chicana el grupo liderado por Acho Estol y Dolores Solá, titulado Ayer hoy era mañana (La chicana, 1997) es también uno de los primeros discos editados de la generación de compositores de tango actual. Consta de quince temas, de los cuales cinco son de tango actual: cuatro de autoría de Estol y uno de Sachetti y Rubín.

En principio, una marca que atraviesa a esta generación es la dimensión temporal como problema: desde la denominación de un grupo de compositores como 'nuevo', 'joven' o 'actual', el conflicto generacional y la pugna por la legitimidad con 'los viejos', ${ }^{6}$ hasta las largas reflexiones que surgen en la mayoría de las entrevistas sobre la relación con el presente (si el tango debe hablar de su tiempo, si lo ha hecho siempre, si es su deber hacerlo ahora). En este primer álbum de La Chicana, el tema se introduce desde el título, con los tres adverbios temporales señalando el pasado, el presente y el futuro. El ayer como referencia ineludible, pero también la relativización del absoluto temporal, la evidencia de que, junto con los tiempos, cambia también el valor de los deícticos: lo que ayer ni se podía imaginar es hoy la realidad. Así, aparecerán los tópicos de la historia del tango, reformulados a lo largo de las composiciones del disco: el farol como anclaje a Buenos Aires, la milonguita y los cuchilleros. 
El tema Una rosa y un farol (Estol, 1997a), desde su título, presenta objetos cristalizados en el imaginario del tango, y por extensión (basta mirar cualquier postal en las zonas turísticas de San Telmo o La Boca) en el imaginario de la ciudad de Buenos Aires. Por un lado, utiliza en su letra los principales tópicos tangueros: la esquina, el farol, la traición de la mujer:

“Te diré que no me importa, yo te quiero como antes/ te perdono cada instante de tu traición/ Solo quiero que aparezcas y volvamos al pasado/a esta esquina de mi vida con la rosa y el farol." Pero rápidamente reintroduce el humor y el presente: "Los vaguitos de la cuadra me tomaron por un cana /y cuando pasó la cana me tomó por taxi boy".

Dos temas hacen referencia al clásico tópico tanguero de la mujer (la Milonguita) ${ }^{7}$ que se fue del barrio buscando el ascenso social y cae en la corrupción de la vida nocturna, abandonando sus orígenes y, sobre todo, la compañía del hombre que narra y/o protagoniza la historia de la canción. Una es La Marilyn, de Rubín (2000a), y otra es Farandulera, de Estol (1997b). Las mujeres de estos tangos se dejan tentar por el lujo y el vicio y, simplemente, se van. La Marilyn de Rubín ya no tiene, como la Milonguita de Delfino y Linning (1920) "la pollera cortona y las trenzas", sino que era, en clara referencia a la estética televisiva de la década del '90, una "Rubia de las platinadas, teñida como esas/ que pasan por tele de jean apretado". También, a diferencia de la versión antigua de la Milonguita, ${ }^{8}$ no se la representa con pena y compasión por su decadencia, sino con ironía y humor: "se comió la película de veras" opina el yo poético cuando describe el cambio de vida de Marilyn. Al final del tango, en un recitado, interpela a su personaje y le dice, casi desconcertado y desde el humor: "Ya lo sé bien que los caminos se han hecho para andarlos, pero el tuyo Marilyn, iQué se yo!¿qué querés que te diga?... iHacé lo que quieras, Marilyn! iHacé lo que quieras!".

Farandulera, de Estol (1997b), también hace referencia a un personaje que trabaja en la televisión. Y, al igual que la Marilyn y que las Milonguitas de toda la historia del tango, las decisiones que la llevaron a su vida actual son

7 Milonguita es un tango de Enrique Delfino y Samuel Linning, de 1920 que cuenta la historia de una chica de barrio que termina corrompida e infeliz por la vida de la noche y el cabaré.

8 El tópico de la milonguita reaparece en numerosos tangos, como El motivo y Flor de fango, de Pascual Contursi, La muerte de Milonguita, de Bonatti y Canaro, Santa Milonguita, de Cadícamo y Delfino y Muñeca brava, de Cadícamo y Visca. narradas por el yo poético como decisiones equivocadas: “Brillarás en las fiestas faranduleras/empresarios poderosos lucharán tu corazón;/ torcerás en tu cabeza quilombera/ la relación entre la guita y el amor". La Farandulera de Estol confunde dinero con amor, así como la Marilyn de Rubín se confunde en el camino que eligió tomar.

Ambas toman el modelo de la Milonguita de la tradición, cuyo ascenso social es siempre precario, ya que logra ascender en riqueza, pero no en estatus social (Savigliano, 1993-94) y que por elegir tener dinero y ascender socialmente es infeliz. Mientras la pobreza es idealizada y vinculada a la felicidad (y generalmente también a la inocencia): "Milonguita/ los hombres te han hecho mal/ y hoy darías toda tu alma/ por vestirte de percal" (Delfino y Linning, 1920). Sin embargo, la referencia es indirecta: se percibe el homenaje a la historia del tango sin nombrarla, ubicando la narración en la actualidad, en el mundo de la televisión de los noventa, la farándula y la referencia a la política contemporánea (la UCD).

En la letra de La patota, de Acho Estol (Estol 1997c), se revive otro tema antiguo del tango en clave moderna. Allí, un grupo de jóvenes, "en la hora de los valientes", como en los duelos de cuchilleros de antaño, "se trenzaban por el honor". "No era un cuento de los veinte, ya existía el rock and roll", aclara la letra, tematizando la referencia a este período. Instaurándose en el verosímil del primer tango, "el tango 'reo' que circulaba en ambientes 'reos'” (Linardi, 2012), pero aggiornado al presente: los compadritos cuchilleros han devenido patota de esquina que escucha a $\mathrm{Manal}^{9}$ y pelea por deporte. Eso hasta la llegada de la dictadura ("se acabó con los milicos la violenta tradición"), que vuelve a anclar temporalmente el relato en las últimas décadas del siglo XX, des-romantizando, de algún modo, el culto al pasado. Así, la tematización de la violencia institucional permite el ingreso de la política contemporánea y transforma la pelea lúdica de la patota en amenaza real y muerte: "el chino terminó preso sin indulto ni perdón/ Al petiso lo mataron en alguna confusión/ el gordo se hizo cana, la puta que lo parió".

Además de las letras, otros elementos en este disco apuntan a la tradición del tango previo a la década de oro. En primer lugar, la instrumentación elegida, con trío de guitarra, flauta y bandoneón, lejos de la sonoridad de la orquesta típica, remite a los primeros tangos del Río

9 Trío musical argentino formado en 1968, considerado uno de los grupos fundacionales del rock nacional. 
de la Plata. ${ }^{10}$ Por otro lado, el repertorio de temas tradicionales elegidos para completar el disco es significativo.

En los discos subsiguientes, los temas de autoría de Acho Estol irán aumentando el número hasta llegar a ser todos o casi todos. El primero tiene solamente cuatro temas de su autoría. En el resto, si bien no obedecen a un criterio temporalmente uniforme, notamos una predominancia del período de comienzos del siglo XX. Así, encontramos los tangos instrumentales de Ángel Villoldo, El esquinazo (s/f) y El porteñito (1903), interpretados a la manera tradicional por dúo de guitarra y flauta. Los temas Chorra, de Enrique Santos Discépolo (1928) y Por una cabeza, de Carlos Gardel y Alfredo Le Pera (1935) aportan el componente gardeliano. Otro artista de referencia, que usaba la sonoridad guitarrística en sus grabaciones y que además aparece en un fotomontaje en el arte del disco. Por último, el disco incluye tres tangos de la década del veinte, compuestos para voz femenina, y poco interpretados y grabados a lo largo de la historia, con un fuerte tono humorístico: La mina del Ford, de Fidel del Negro, Antonio Scatasso y Pascual Contursi (1924), Gorda, de Luís Martino y Camilo Darthes (s/f) y ¿Qué querés con ese loro?, de Enrique Delfino y Manuel Romero (1929).

Esta elección se enmarca en uno de los rasgos salientes de los autores del "tango actual", que es lo que Mercedes Liska observa como "producciones musicales fuertemente ligadas con lo festivo: carácter emergente del tango en sus inicios" (Liska 2012, p. 81). Estos temas resaltan el componente humorístico en el arreglo y el carácter actoral de la voz femenina, marca característica de La Chicana, con la interpretación de Dolores Solá homenajeando de alguna forma a las primeras mujeres cantoras del tango, como Rosita Quiroga, Azucena Maizani, Sofia Bozán y Tita Merello.

\section{El ‘Tape' Rubín: Hemisferios}

Como Borges, pero en broma, el 'Tape' Rubín se auto adjudica una genealogía maleva. Cuando en una entrevista le preguntan por el origen de su apodo, improvisa una serie de opciones para que el periodista elija:

\begin{abstract}
A) Un antepasado - tío- orillero y pendenciero de Uruguay: el Tape Olmedo. B) Un episodio confuso en la milonga Regin, donde termina borracho y rodeado por 54 milongueras que lo bautizan así; C) La aparición de un misterioso ser en 1984, que le pone igual; D) Su obsesión por el walkman desde chico. (Rubín, citado en Página 12, 2009, PÁGINA. 1)
\end{abstract}

Al final de la entrevista, cuando el periodista le pide una definición, le dice, entre risas, que elija la primera: "Poné la del tío pendenciero..." (Página 12, 2009, PÁGINA 12). La filiación ficticia, si bien en clave humorística, o incluso aún más por eso, establece un lazo que une a este autor, como también señalábamos en el caso de Estol, con las décadas del veinte y treinta.

Los mismos términos 'orillero' y 'pendenciero' remiten a ese período, así como el componente de humor que prácticamente se había perdido en el tango del cuarenta. Al igual que La patota de Estol (1997c), aquí el relato de compadritos llega resignificado, yuxtapuesto a otros tiempos: el año 1984, el walkman. Este mosaico temporal lo arranca del gesto del tributo o la copia de los viejos, ubicándolo en una mitología deliberadamente inventada, hecha de mezcla de tradiciones.

Rubín también elige una instrumentación de conjunto chico: comienza con el Cuarteto Almagro (violín, bajo, bandoneón y piano) con el que graba solamente el primer disco, Hemisferios, en el año 2000, disco que analizaremos en esta oportunidad. Luego gira hacia el formato con el que sigue hasta hoy en día y que mejor pareciera adaptarse a su música: el trío de guitarras. Con las guitarras de Puente Alsina ${ }^{11}$ grabó Reina noche (2004) y Lujo total (2009) y luego, incorporando la guitarra de Leandro Nikitoff, Cambiando cordaje (2018).

En Hemisferios, solamente cuatro tangos son cantados, todos de autoría de Rubín: Bluses de Boedo (2000b), Lysou (2000c), Ella se fue (2000d) y La Marilyn (2000a). Completan el disco varios temas instrumentales de autoría de Rubín y tres tangos de Astor Piazzolla, elección que muestra el amplio rango de influencias de esta generación.

11 Las guitarras del puente Alsina es un trío integrado por Alfredo Rubín, Adrián Lacruz y Mariano Heller. 
En Bluses de Boedo (Rubin, 2000b) encontramos la misma convivencia de pasado con presente que encontrábamos en La Chicana: "La radio escupe y chilla su marketing de baba/ la droga no progresa/ se lamenta el buey jipón/ Silbando bien milonga yo me abro calle abajo/ los bluses de Boedo cruzan por mi corazón". Como vemos ya desde la primera estrofa del tema, los temas tradicionales del tango (el silbido 'bien milonga', el barrio de Boedo) se combinan con neologismos modernos (el 'marketing de baba') y el tango se mezcla con el blues referencia a la música extranjera, pero adaptada a la jerga porteña.

El plural 'bluses' para el término en inglés blues, al igual que el neologismo 'jipón', una porteñización de la palabra en inglés hippie, señalan un lunfardo moderno en el que se ensanchó el vocabulario para seguir incorporando nuevos términos sin desechar los antiguos. Lo mismo ocurre en este tema en el plano musical: el arreglo en estilo de tango se funde por momentos con recursos propios del blues (como el uso de la escala pentatónica, la blue note ${ }^{12}$ y las progresiones armónicas típicas del género ${ }^{13}$ pero sin abandonar los yeites ${ }^{14} \tan$ gueros ni romper con la sonoridad del resto del disco.

Los otros tres temas (con letra) de autoría de Rubín, Ella se fue, Lysou y La Marilyn representan tres versiones de la figura de la mujer frecuentes en los tangos clásicos: son mujeres que se van, que dejan al varón abandonado, hundido en lamentos, romances terminados o amores fallidos. Son tópicos tangueros cristalizados, tomados de la tradición, pero reformulados en el presente. Por otro lado, las tres obras pertenecen a tres subgéneros diferentes del tango: la primera es una milonga, la segunda un tango y la tercera un vals. A La Marilyn, también grabada por La Chicana, ya nos referimos anteriormente. En Ella se fue y Lysou, encontramos el tema del abandono a través de la mirada del amante desahuciado que relata la historia a través de imágenes y sensaciones, sin seguir una narración lineal.

12 En el blues, es un recurso frecuente agregar la quinta disminuida (u oncena aumentada) a la escala pentatónica menor. La tercera menor, séptima menor y quinta disminuida son conocidas como blue note.

13 Es característico del blues el uso de tríadas mayores con séptima menor, pero sin función dominante, como el IV7 que aparece en este caso.

14 Se utiliza el término lunfardo yeite para referirse a los recursos estilísticos típicos del tango que le otorgan su sonoridad característica.
Ella se fue (Rubin, 2000d) es una milonga a la manera tradicional, con una melodía, letra y tímbrica criolla, cantada a dos voces, al estilo de muchas milongas de principio de siglo XX. Allí narra en un lunfardo exacerbado (casi no hay un verso sin lunfardismos) la historia de la mujer abandónica que deja al amante hundido en lamentos, sin comprender lo que pasó: “Un chicotazo en la raca,/ corte de rostro violento/ mugre de biorsi en el alma/ ella se fue."

La letra de Lysou (Rubin, 2000c) estilísticamente se mueve incluso un poco más allá de lo tradicional. En su comienzo dice: "Una fuga, una ráfaga, un flash", da la pista del estilo que seguirá toda la letra, combinando el relato con imágenes yuxtapuestas en un estilo casi cubista, que juega con el sonido y el sentido de las palabras, desarmándolas. Así ocurre en el estribillo, en donde combina la metáfora y la aliteración: "agua de luz/ polvo de luz/ sombra de luz/ Lysou."

Como propone en una entrevista, las influencias a su composición son variadas. Y esto, lejos de interpretarlo como un alejamiento con la tradición, lo explica como un retorno a ella:

Yo soy lector de En la Masmédula de Oliverio Girondo y eso me pegó, de ahí las sílabas sueltas, las fotos tiradas así. Además, hay que ver que cuando el tango se desenvolvía naturalmente, antes que se lo elimine de la vida de la ciudad, tomaba elementos de todas las culturas del mundo. (Rubín, citado en Página 12, 2009, PÁGINA.4)

De esta forma, vemos como en Hemisferios, el primer disco del Tape Rubín, conviven diferentes estéticas y sonoridades, que van desde la referencia criolla y el lunfardo de antaño a los neologismos y la presencia, temática y estilística, de nuevas formas musicales, como el blues.

\section{Juan Vattuone: Tangos al mango}

Si bien el debut discográfico de Juan Vattuone llegó recién en el año 2005 con Tangos al mango, él fue uno de los primeros artistas de esta nueva generación en componer tangos. Muchos de sus temas datan de las décadas del ochenta y noventa y fueron cantados numerosas veces en distintos escenarios.

Al igual que Estol, Vattuone realiza en su primer disco un homenaje a la figura de Carlos Gardel. El tema Sos 
Gardel (Vattuone, 2005a) comienza con un recitado en tono costumbrista en el que alucina una presencia del ídolo tanguero en el paisaje de la infancia. Y como Estol y Rubín, Vattuone opta por una sonoridad de principios de siglo XX, primando el acompañamiento de guitarras o conjuntos pequeños con guitarra y bandoneón en casi todos los temas. Por lo menos en casi todos los tangos, pues en este álbum también aparecen otras instrumentaciones y otros géneros, como el rock y el candombe. Sin embargo, el modo de cantar de Vattuone (la impostación de la voz, los giros melódicos, el vibrato), a diferencia del de Estol y Rubín, emula a los grandes cantores de la época de oro, de los cuales se considera discípulo.

En las obras de Vattuone, el uso del lunfardo se combina con un realismo de denuncia que remite al grupo de Boedo, ${ }^{15}$ contemporáneo al tango de la década del treinta. Así ocurre, por ejemplo, en la historia en clave melodramática de Pablito el grande (2005 b), el niño que lustra botas y sueña con tener un cajón nuevo: "Todos los chicos les piden cosas/ la bicicleta, otro un reloj/ yo solo quiero un cajón nuevo/ porque el que tengo se me rompió."

El juego entre el pasado y el presente, al igual que observábamos en Estol y Rubín, es permanente. Encontramos, por ejemplo, el uso del tradicional lunfardo tanguero, así como los clásicos tópicos del barrio de infancia y el abandono del ser amado, yuxtapuestos a neologismos e historias impensables para el tango de períodos anteriores, como el romance del policía torturador con la travesti que narra en El yuta Lorenzo (Vattuone, 2005c): “Lo dejó un travesti al yuta Lorenzo/ le quitaba el vento dijo algún boliau/ él, que era tan macho pa' torturar gente/ se vio de repente tan arrodillao".

En Un chabón jailaife (Vattuone 2005d) se hace referencia al tango Dandy (Demare, Irusta y Fugazot, 1928), del que es un homenaje o una suerte de traducción al presente en clave invertida. En el tango de Demare, Irusta y Fugazot, el 'chabón' es un 'seco' que se hace

15 El grupo de Boedo fue un conjunto de escritores de principios de Siglo XX, que compartían el propósito de narrar la Buenos Aires de su tiempo y los conflictos que la atravesaban desde el punto de vista de los inmigrantes y los obreros (la pobreza, la miseria, el trabajo alienante y humillante y la vida en los barrios "bajos» de la ciudad). Estilísticamente, el realismo era pensado por este grupo como la voluntaria llaneza en pos de una comunicación didáctica y de denuncia, en oposición al grupo de Florida (Con Borges y Ocampo a la cabeza) que sostenían una estética vanguardista, siguiendo las corrientes literarias en boga en Europa (García Cedro, 2006). pasar por 'niño bien', en cambio, en la historia de Vattuone, el personaje, tras caer en desgracia, deja de ser un 'Jailaife' para convertirse en un trabajador: "Y cuando escucha 'Dandy' por la radio/se acuerda de su vida quilombera/ hoy anda con la pilcha del laburo/ y se lo ve feliz, tejiendo como una abuela". El 'chabón Jailaife' de Vattuone recorre el camino contrario a la Milonguita. Y, a diferencia de ella, él tiene un final, aunque en clave irónica, feliz.

La ironía también está presente en la milonga La chacón de mi naerma (2005e), donde ridiculiza la posición del hermano 'guardabosques', ${ }^{16}$ que quiere controlar la sexualidad de su hermana. Poniendo en evidencia, de paso, el machismo presente en el tango y el estereotipo del 'macho argentino'. Su tono es juguetón e irónico, pero como siempre va directo al hueso, sin rodeos, y apunta directamente al lugar incómodo: "No quiero que se masturbe/ porque sé que eso hace mal/ que ella cuide a mi viejita/ que le dé felicidad/ Mi hermana es como una santa/ es igual a mi mamá". El uso del humor es explicado por Vattuone como parte de la herencia del primer tango:

Lo que hago es recuperar aquello del origen del tango, cuando era carcelario, prostibulario y las letras eran pequeñas crónicas humorísticas o testimoniales. Canto las cosas más terribles con humor - afirma-. El lunfardo es una jerga que casi está en extinción, por eso me gusta. (Vattuone, citado en Plaza, 2003, PÁGINA. 7)

Si bien el origen supuestamente 'prostibulario' del tango ha sido ya cuestionado (Carozzi, 2015; Benedetti, 2015), es a esa estética y mitología que remiten muchas de las composiciones de los nuevos tangueros. Como señala Mercedes Liska, se puede observar en una vertiente del tango actual un gesto de distancia hacia la marca de nostalgia y melancolía, que había quedado anclada a la representación del tango clásico, a través de una "puesta en valor del lunfardo, alusivo a un tango hermético codificado socialmente y enclasado en los sectores populares" (Liska, 2012, p. 81). Es decir, en respuesta al lenguaje canonizado y fijado en el imaginario social de la época de oro del tango, algunos autores rescatan este modo de hacer tango de las primeras décadas del siglo XX, opacado por las poéticas del siguiente período, que viraron hacia el melodrama y la nostalgia (Savigliano, 1993-94) y que fueron "apaciguándose" y

16 Lunfardo que designa un varón celoso y excesivamente protector de una mujer, usualmente la madre o la hermana. 
"sentimentalizándose" cuanto más se acercó a la cultura moral burguesa" (Liska, 2012, p. 81).

Por último, la referencia a la situación política y social actual atraviesa casi todas sus letras. Por ejemplo, en Misántropo (Vattuone, 2005f) que, como explica cada vez que lo canta en vivo, está dedicado a un expresidente de la década del 90 que prefiere no nombrar. Allí, no ahorra en adjetivos que expresen su desprecio: "Sos alcahuete de los buchones/ un farabute bien nacional/ te armaste un mundo de mascaritas/ todas las fotos son para vos/ Cuando el de arriba te mande en cana/ para tu cama no habrá colchón."

Lo mismo ocurre en Ni olvido ni perdón, tema que abre el disco, donde hace alusión al 'corralito'17 del 2001 y a la última dictadura militar:

“No me resigno a tanto espanto/ hambre, llanto/ Hay tanta gente sin laburo, tristes, duros/ La dignidad se la vendieron a un finao/ el corralito en el banco del mamao/ y a la justicia que es divina/ y a mi Argentina la han empomao".

El tanguito del nefasto general (Vattuone, 2005g), tema que cierra el disco, reivindica en la letra su modo de denuncia para componer. Este tema, si bien se denomina tango en el título, se presenta como un híbrido genérico. Ni la melodía de la voz ni la instrumentación remiten al tango. Si bien acompaña una guitarra, también se escucha la batería y por momentos un kazoo ${ }^{18}$, que aporta un cierto aire humorístico a la sonoridad del tema. El toque de la guitarra, además, se acerca al acompañamiento de swing ${ }^{19}$, por la secuencia armónica y también por el ritmo en negras, donde a su vez resuena al marcato característico del tango.

17 El 'corralito' fue el término con que se denominó, en Argentina, a la restricción de la libre disposición de dinero en efectivo (de plazos fijos, cuentas corrientes y cajas de ahorros) impuesta por el gobierno de Fernando de la Rúa en diciembre de 2001 hasta diciembre del año siguiente.

18 El kazoo es conocido también como kazí, cazú, pito de carnaval, militón, turuta o flauta. Es un instrumento musical de viento de la familia de los membranófonos. Es considerado uno de los instrumentos musicales más fáciles de tocar y es muy popular en ámbitos de enseñanza musical para niños. Sin embargo, también ha sido utilizado por músicos profesionales de todo el mundo.

19 El swing, es un estilo de jazz que se originó hacia fines de la década del 20 en Estados Unidos, convirtiéndose en uno de los géneros musicales más populares del país durante la década del 30.

\section{A modo de conclusión}

A partir de lo analizado hasta aquí observamos que, por un lado, los tres autores eligen una sonoridad de grupo pequeño, con una instrumentación que remite al período anterior a la cristalización de la orquesta típica. Si bien es cierto que en la época en la que surgen estos nuevos autores, con el escaso público que el tango tenía, costear una orquesta hubiera sido casi imposible, esta estética de principio de siglo XX es defendida tanto en lo musical como en el plano poético.

Por otro lado, en cuanto al aspecto temático de las letras, encontramos en los tres autores referencias a la marginalidad del tango y el uso del lunfardo como identitario de un grupo social excluido, resaltando el carácter dramático de la realidad. Pero, a la vez combinando con elementos humorísticos o festivos propios de las décadas del veinte y treinta (Liska, 2012). Así, los temas sociales, que habían sido expulsados del tango en la década del cuarenta, junto con el humor, vuelven en esta nueva generación con una presencia preponderante. La referencia no es inconsciente: hay una autoconciencia muy marcada, repetida en las letras y las entrevistas, de tomar como tradición las composiciones de un período por sobre el otro.

Este estilo de escritura poética será retomado por una gran parte de los nuevos autores que les siguieron, sobre todo en el ingreso de temas sociales, al estilo Vattuone (por ejemplo, los tangos de Juan Lorenzo, Cintia Trigo, Victoria di Raimondo, Pablo Sensottera, entre otros). Como resalta Julián Peralta ${ }^{20}$ en una entrevista, los compositores actuales reconocen el carácter de pioneros a estos autores, a quienes gran parte de los músicos más jóvenes versionaron y grabaron ${ }^{21}$ : “También está el tema del Tape Rubín, que es uno de los

20 Julián Peralta es un pianista, director, compositor y docente argentino de reconocida trayectoria. Fundó y dirigió la Orquesta Típica Fernández Fierro, el sexteto Astillero, la Orquesta Típica Julián Peralta, y organizó espacios independientes y autogestionados de desarrollo del movimiento del tango, como La Máquina Tanguera, el Club Atlético Fernández Fierro, Milonga en Orsai y la Escuela y el Teatro Orlando Goñi, entre otros. Es docente en la Esscuela de Música Popular de Avellaneda y la escuela Orlando Goñi.

21 Por citar algunos ejemplos, en 2012, la Orquesta Típica Julián Peralta incluye un tema de Rubín (Regin) y un tema de Estol (Mi involución) en el repertorio del disco Un disparo en la noche. En el siguiente disco de esta orquesta, Un disparo en la noche 2 (2016) se incluye Aire sin final, de Rubín. este último tango fue versionado por numerosas orquestas, como Chifladas tango. En ese mismo año, Patricia Malanca incluyó un tema de Rubín (Milonguera de ley) y uno de Estol (Juguete rabioso) en su disco Bucles. El cantante 'Cucuza' 
pioneros en esto. Viene laburando hace años y arrancó muy solo. Tanto él como el laburo de La Chicana y Juan Vattuone, que son trabajos pioneros". (Peralta citado en Plaza, 2011, PÁGINA. 5).

Así, estos autores hablan del presente en un progreso que consiste en cambiar el ayer por el anteayer. Pero el movimiento, como vimos, no termina allí: el tango pre-década de oro se combina con el rock nacional, el blues y el folclore, incorporando así nuevos elementos y lenguajes en el tango actual. Los tópicos recurrentes del tango clásico, como la milonguita, el paisaje de barrio y el malevo, siguen apareciendo, pero en clave actual, tanto en el vocabulario elegido como en las historias que se narran. El lunfardo de antaño se combina en las letras con neologismos o expresiones propias del final del siglo XX, como el marketing de baba del Tape Rubín (2000b), pues la realidad social que buscan representar, si bien comparte el dramatismo de la década del treinta, ha cambiado e incluye, por ejemplo, a la dictadura militar (en La patota de Estol o en $\mathrm{Ni}$ olvido ni perdón, de Vattuone), y no teme incluir sujetos tradicionalmente excluidos del tango 'macho', como la travesti de El yuta Lorenzo de Vattuone. Además, hacen un uso más libre de la armonía y la melodía tanguera y se reconocen herederos de una tradición impura, donde el tango se mezcla con el blues y el rock nacional. Como escribe Vattuone en "Ni olvido ni perdón" (2005h): "Me hago eco de García/ y no del que está en la guía/ sino Charly say no more".

Quizás estas nuevas raíces se construyan con elementos tan heterogéneos, porque la tradición tanguera, en los años noventa, había quedado dispersa y con pocas columnas en pie. Ya no alcanza la década de oro, cristalizada e idealizada en el imaginario colectivo, ni tampoco la tradición del tango anterior, 'reo y compadrito', como gustan llamarlo estos compositores. Así, se encuentran en la necesidad de crear nuevas bases, que incorporen tanto el viejo tango como aquello que ocurrió en la música, la lengua y la historia nacional en las últimas décadas. Es en la confluencia de estas búsquedas que estos 'pioneros' pudieron trazar las primeras líneas para desarrollar una nueva estética en el tango canción.

Castiello, por su parte, grabó de Estol Juguete rabioso y Origami en su disco Tango Bardo, de 2017 y Te vas a hacer golpear en Castiellos (2018).

\section{Referencias}

Adorni, A. (2016). Sonoridades del tango hoy: un análisis de las nuevas composiciones para orquesta típica, en Mercedes Liska y Soledad Venegas (Comps.) Tango. Ventanas del presente II. De la gesta a la historia musical reciente. Buenos Aires: Desde la gente.

Alfredo Rubín y las Guitarras de Puente Alsina. (2004). Reina Noche (CD). Buenos Aires: Acqua Records.

(2009). Lujo total (CD). Buenos Aires: Acqua Records.

Amato, M. (2016). Tras la memoria negra: 'Dolor Wolof' y 'Fantasmas africanos', de Acho Estol, en Ezequiel Ferriol (Comp.) Actas de las I Jornadas de Lenguaje, Literatura y Tango: cruces entre la lingüística, la crítica literaria y el psicoanálisis. Buenos Aires: La docta ignorancia.

Benedetti, H. (2015). Nueva historia del tango. De los orígenes al siglo xxi. Buenos Aires, Argentina: Siglo xxi Editores.

Carozzi, M. (2015). Aquí se baila el tango: una etnografía de las milongas porteñas. Buenos Aires, Argentina: Siglo xxi Editores

Clarín (2004). Mi tango es transgresor. Recuperado de: https://tinyurl.com/xs775b7c

Cuarteto Almagro. (2000). Hemisferios. (CD). Buenos Aires: Acqua Records.

Delfino, E. y Romero, M., [1929]. ¿Qué querés con ese loro?, en La Chicana (1997). Ayer hoy era mañana (CD). Buenos Aires: Independiente.

Delfino, E. y Linning, S., [1929]. Milonguita (Esthercita) en De Angelis, A., (1953). Buenos Aires: AMD-EMI.

Del Negro, F., Scatasso, A. y Contursi, P. [1924]. La mina del Ford. En La Chicana. (1997) Ayer hoy era mañana (CD). Buenos Aires, Argentina: Independiente.

Demare, L., Irusta, A. y Fugazot, R. [1928]. Dandy, en Juárez, Rubén (1972) Viejos tangos con Rubén Juarez. (CD) Buenos Aires: EMI Odeón.

Discépolo, E. [1928]. Chorra, en La Chicana (1997). Ayer hoy era mañana (CD). Buenos Aires: Independiente. 
Estol, A. (1997a). Una rosa y un farol, en Ayer hoy era mañana (CD). Buenos Aires: Independiente.

(1997b). Farandulera, en Ayer hoy era

mañana (CD). Buenos Aires: Independiente. . (1997c). La patota, en Ayer hoy era mañana (CD). Buenos Aires: Independiente.

García Cedro, G. (2006) Boedo y Florida. Una antología crítica. Buenos Aires, Argentina: Losada.

Gardel C. y Le Pera, A. [1935] en La Chicana (1997) Por una cabeza, en Ayer hoy era mañana (CD). Buenos Aires: Independiente.

Greco, M. (2012). “34 puñaladas en el escenario del tango actual", en Mercedes Liska y Soledad Venegas (Comps.) Tango. Ventanas del presente. Miradas sobre las experiencias musicales contemporáneas. Buenos Aires: Ediciones del CCC.

Juárez, C. y Virgili, M. (2012) “Contrapunto y enunciación en la Orquesta Típica Fernández Fierro", en Mercedes Liska y Soledad Venegas (Comps.) Tango. Ventanas del presente. Miradas sobre las experiencias musicales contemporáneas. Buenos Aires: Ediciones del CCC.

La Chicana. (1997) Ayer Hoy Era Mañana (CD). Buenos Aires: Independiente.

Lakner, H. (2017) “El 'gótico surero' en la estética de La Chicana y en la poética de Acho Estol", en Ezequiel Ferriol (Comp.) Actas de las I Jornadas de Lenguaje, Literatura y Tango: cruces entre la lingüística, la crítica literaria y el psicoanálisis. Buenos Aires: La docta ignorancia.

Linardi, S. (2012) “Dónde estará mi arrabal. Un recorrido por las letras del nuevo tango en Buenos Aires", en Mercedes Liska y Soledad Venegas (Comps.) Tango. Ventanas del presente. Miradas sobre las experiencias musicales contemporáneas. Buenos Aires: Ediciones del CCC.

Liska, M. (2012). “Entre opacidades y oscuridades. Algunas reflexiones sobre las nuevas estéticas musicales", en Mercedes Liska y Soledad Venegas (Comps.) Tango. Ventanas del presente. Miradas sobre las experiencias musicales contemporáneas. Buenos Aires: Ediciones del CCC.
Lucker, M. (2007). "Tango Renovación: On the Uses of Music History in Post-Crisis Argentina", en Revista de Música Latinoamericana, Vol. 28, No. 1.

Marcos, G. (2012). El Poder del Grupo, en Mercedes Liska y Soledad Venegas (Comps.) Tango. Ventanas del presente. Miradas sobre las experiencias musicales contemporáneas. Buenos Aires: Ediciones del CCC.

Martino, L. y Darthes, C., Gorda. [s.f.], en La Chicana (1997) Ayer hoy era mañana (CD), Buenos Aires: Independiente.

Mertz, M (2018). Vuelve el tango. Análisis de las letras de tango (1999-2013). Buenos Aires: Milena Caserola.

Micheletto, K. (2003). Charly García podría ser nuestro Discépolo de hoy, en Página/12,. Recuperado de: https://tinyurl.com/4dwup6cv

Ocantos, H. (2016). “El humor, la parodia y la crítica social en las letras de tango del siglo xxi", en Ezequiel Ferriol (Comp.) Actas de las I Jornadas de Lenguaje, Literatura y Tango: cruces entre la lingüística, la crítica literaria y el psicoanálisis. Buenos Aires: La docta ignorancia.

Página 12 (2009). Hacer tango es algo natural. Recuperado de: https://tinyurl.com/kkmtnkr2 Plaza, G. (2003). Un tanguero como los de antes, en La Nación. Recuperado de: https://tinyurl.com/383s9js5

Plaza, G. (2011). Julián Peralta: La selección de los tangos nuevos, en La Nación. Recuperado de: https:// tinyurl.com/522mzm27

Pujol, S. (2012). Cien años de música argentina. Buenos Aires: Biblos.

Rubín, A. (2000a). La Marilyn, en Hemisferios (CD). Buenos Aires: Acqua Records.

(2000b). Bluses de Boedo, en Hemisferios

(CD). Buenos Aires: Acqua Records.

(2000c). Lysou, en Hemisferios (CD).

Buenos Aires: Acqua Records. (2000d). Ella se fue, en Hemisferios (CD). Buenos Aires: Acqua Records.

Rubín, Lacruz, Heler, Nikitoff. (2018). Cambiando

Cordaje (CD). Buenos Aires, Argentina: Club del Disco. 
Savigliano, M. (1993-94). "Malevos Ilorones y percantas retobadas: el tango como espectáculo de razas, clase e imperialismo", en Relaciones de la sociedad Argentina de Antropología, No. 19.

Vattuone, J. (2005) Tangos al mango (CD) Buenos Aires: Fonocal.

(2005a). Sos Gardel, en Tangos al mango (CD) Buenos Aires: Fonocal.

(2005b). Pablito el grande, en Tangos al mango (CD) Buenos Aires: Fonocal.

(2005c). El yuta Lorenzo, en Tangos al mango (CD) Buenos Aires: Fonocal.

(2005d). Un chabón jailaife, en Tangos al mango (CD) Buenos Aires: Fonocal. . (2005e). La chacón de mi naerma, en Tangos al mango (CD) Buenos Aires: Fonocal. . (2005f). Misántropo, en Tangos al mango (CD) Buenos Aires: Fonocal. (2005g). El tanguito del nefasto general, en Tangos al mango (CD) Buenos Aires: Fonocal.

. (2005h). Ni olvido no perdón, en Tangos al mango (CD) Buenos Aires: Fonocal.

Villoldo, A. [s.f] El esquinazo, en La Chicana. (1997) Ayer hoy era mañana (CD). Buenos Aires: Independiente.

[1903] El porteñito, en La Chicana. (1997) Ayer hoy era mañana (CD). Buenos Aires: Independiente. 